\title{
Penggunaan Genogram dalam Deteksi Dini Faktor Risiko Penyakit Degeneratif dan Keganasan di Masyarakat
}

\author{
Nita Arisanti, Sharon Gondodiputro, Henni Djuhaeni \\ Departemen Ilmu Kesehatan Masyarakat, Fakultas Kedokteran Universitas Padjadjaran Bandung
}

\begin{abstract}
Abstrak
Penyakit tidak menular (PTM) dapat dimulai sejak usia produktif. Umumnya masyarakat baru memeriksakan diri setelah timbul gejala, padahal deteksi dini penyakit penting dilakukan. Sebagian penyakit bersifat familial atau diturunkan yang dapat dideteksi dini dengan menggali riwayat penyakit individu dan keluarga. Genogram merupakan salah satu alat untuk menggali faktor risiko dalam keluarga. Tujuan penelitian ini adalah mengetahui sejauh mana fungsi genogram dalam mendeteksi dini faktor risiko penyakit keganasan dan degeneratif. Penelitian kuantitatif dilakukan terhadap 231 pasien di puskesmas se-Kota Bandung. Kriteria inklusi adalah pengunjung puskesmas, berusia 18 tahun ke atas, kooperatif, dan bersedia diwawancara. Teknik pemilihan sampel menggunakan cluster sampling. Pengambilan data menggunakan kuesioner genogram yang mencatat faktor risiko PTM dari 3 generasi. Dilakukan analisis genogram dan disajikan dalam tabel distribusi frekuensi. Penelitian ini dilakukan pada bulan Agustus-September 2013. Hasil penelitian menunjukkan, sebanyak 183 dari 231 responden mempunyai faktor risiko penyakit degeneratif dan keganasan yang tergambar dari genogram. Dari riwayat keluarga, penyakit terbanyak adalah hipertensi dan penyakit jantung yang didapatkan dari generasi bapak. Penelitian ini memperkuat penelitian mengenai fungsi genogram yang efektif untuk mendeteksi secara cepat faktor risiko penyakit degeneratif dan keganasan pada individu dan keluarga. [MKB. 2016;48(2):118-22]
\end{abstract}

Kata kunci: Degeneratif, deteksi dini, faktor risiko, genogram, keganasan

\section{Genogram as An Early Detection Method for the Risk Factors of Degenerative Diseases and Malignanciesy in the Community}

\begin{abstract}
Non-communicable diseases (NCDs) can be found at young age and the people are not aware about the diseases. People seek medical care after symptoms occurred. Most of NCDs are familial or hereditaryy; hence, require family explorationin the detection that should be detected by exploring family history. Genogram is tool for describing multigenerational risks. The purpose of this study was to determine the functions of genogram in the early detection of risk factors for degenerative diseases and malignanciesy. A quantitative study was conducted on 231 patients who visited primary health centers (Puskesmas) in Bandung with the inclusion criteria were of patients at visited the selected Puskesmas, aged 18 years, and more, cooperative, and willing to be interviewed. Sampling technique used was cluster sampling. Data collecting were performed using questionnaires that recorded genogram and risk factors from three previous generations of the family. Interpretation of genogram was used to analyze the risk factors. This study was conducted from August to September 2013. The results showed that 183 of 231 respondents have risk factors for degenerative diseases and malignancies, which was reflected from the family genogram. Based on family history, most of respondents had have risk factors for hypertension and heart disease, specifically obtainedespecially from the father's side. from father's generation. This research study confirms the results of previous research studystudies that the on the function of genogram that is effectiveo for in detecting the risk factors for degenerative diseases and malignancies in individuals and families in the community. [MKB. 2016;48(2):118-22]
\end{abstract}

Key words: Degenerative diseases, early detection, genogram, malignancy, risk factors

Korespondensi: Nita Arisanti, dr., MSc., CMFM, Departemen Ilmu Kesehatan Masyarakat Fakultas Kedokteran Universitas Padjadjaran Bandung, Jalan Prof. Eijkman No. 38 Bandung, mobile 08122386276, e-mail nitarisanti@yahoo.com 


\section{Pendahuluan}

Prevalensi penyakit tidak menular (PTM) dari tahun ke tahun meningkat dan di beberapa negara berkembang sudah mengambil alih prevalensi penyakit menular sebagai prevalensi tertinggi. ${ }^{1}$ Badan Kesehatan Dunia (WHO) memperkirakan, tahun 2020 PTM menyebabkan 73\% kematian dan 60\% seluruh kesakitan di dunia. ${ }^{2}$ Keadaan ini terjadi pula di Indonesia. Transisi epidemiologi paralel dengan transisi demografi telah mengakibatkan perubahan pola penyakit dari penyakit infeksi ke PTM. ${ }^{3}$ Riskesdas 2013 menemukan terjadi peningkatan prevalensi hipertensi dari 7,6\% tahun 2007 menjadi 9,5\% tahun 2013. Prevalensi strok meningkat dari 8,3 per 1.000 tahun 2007 menjadi 12,1 per 1.000 tahun 2013 serta prevelensi diabetes melitus meningkat dari 1,1\% tahun 2007 menjadi $2,1 \%$ tahun $2013 .{ }^{3}$ Hal ini merupakan dampak perubahan gaya hidup seperti merokok, kurang aktivitas fisik, konsumsi makanan tinggi lemak dan kalori, serta konsumsi alkohol. ${ }^{2}$ Hasil Riskesdas tahun 2007 memperlihatkan perilaku merokok pada penduduk usia 15 tahun ke atas masih belum menurun bahkan cenderung lebih meningkat dari 34,2\% tahun 2007 menjadi $36,3 \%$ tahun 2013 . $^{3}$

PTM tanpa disadari masyarakat sudah dapat dimulai sejak usia produktif dan masyarakat baru memeriksakan diri setelah timbul gejala. Status sehat dan sakit merupakan suatu keadaan sangat dinamis yang dapat berubah dalam waktu singkat dan tidak dapat diperkirakan. Hal ini berimplikasi bahwa untuk menjadi sehat tidak hanya dapat diselesaikan dengan pengobatan, tetapi keadaan sehat harus dipelihara terus menerus dengan melakukan upaya preventif dan promotif. ${ }^{2} \mathrm{Hal}$ ini tentu saja dapat dilakukan bila pada usia muda penyakit-penyakit seperti penyakit degeneratif dan keganasan sudah mulai dideteksi. Salah satu upaya yang dapat dilakukan untuk deteksi dini adalah menggali riwayat penyakit individu dan keluarga terutama untuk penyakit-penyakit yang sudah diketahui dapat diturunkan. ${ }^{4}$

Genogram adalah pohon keluarga yang menggambarkan faktor biopsikososial individu dan keluarga dalam 3 generasi. Genogram dapat pula menggambarkan siklus hidup keluarga, penyakit, dan hubungan antaranggota keluarga. Kegunaan genogram adalah untuk mengetahui hubungan di antara anggota keluarga, masalah medis dan psikologis keluarga yang sederhana, mudah, cepatserta murah. Informasi yangdidapat dari genogram dapat digunakan oleh seorang dokter untuk mengambil keputusan terhadap masalah pasien dan keluarganya. ${ }^{5}$ Di Indonesia penggunaan genogram sebagai alat deteksi yang diharapkan mampu mengungkapkan faktor risiko dalam sebuah keluarga belum banyak digunakan dalam praktik sehari-hari sehingga perlu diteliti dengan harapan penggunaan genogram ini dapat menjadi salah satu prosedur dalam mengelola pasien dan keluarga pada praktik dokter. Tujuan penelitian ini adalah mengetahui sejauh mana fungsi genogram dalam mendeteksi dini faktor risiko penyakit keganasan dan degeneratif.

\section{Metode}

Penelitian kuantitatif dilakukan terhadap pasien yang datang ke puskesmas di Kota Bandung. Teknik pemilihan sampel menggunakan cluster sampling berdasarkan wilayah di Kota Bandung. Terdapat 4 wilayah terpilih, yaitu Puskesmas Tamblong, Puskesmas Ciumbuleuit, Puskesmas Padasuka, serta Puskesmas Ibrahim Aji. Dari tiap-tiap klaster responden dipilih dengan cara proporsional berdasarkan jumlah kunjungan per bulan. Kriteria inklusi adalah pengunjung puskesmas, berusia 18 tahun ke atas, kooperatif, dan bersedia diwawancarai. Pengambilan data dilakukan dengan wawancara dan menggunakan genogram yang dapat memuat simbol-simbol terstandar menggambarkan faktor risiko dari 3 generasi terdahulu. Lalu, dilakukan interpretasi genogram dan analisis data memakai distribusi frekuensi. Informed consent diperoleh sebelum penelitian dilakukan. Penelitian dilakukan pada bulan Agustus sampai September 2013.

\section{Hasil}

Pada penelitian ini didapatkan bahwa sebanyak 183 dari 231 responden $(79,2 \%)$ mempunyai faktor risiko terhadap penyakit keganasan dan degeneratif. Responden pada penelitian ini berusia 45-54 tahun sebanyak 28,6\%. Berdasarkan jenis kelamin, didapatkan lebih banyak responden perempuan (62\%) yang berusia di atas 45 tahun. Sebagian besar $(74,9 \%)$ responden sudah menikah, $73,2 \%$ responden merupakan generasi kedua, yaitu sebagai anak. Faktor risiko yang terdeteksi dari genogram adalah merokok baik sebagai perokok aktif maupun pasif. Pada Tabel 2 terlihat 22,5\% responden perokok aktif dan $41,1 \%$ mempunyai anggota keluarga yang merokok.

PTM yang terdeteksi pada genogram adalah keganasan, hipertensi, diabetes melitus, strok, 
Nita Arisanti: Penggunaan Genogram dalam Deteksi Dini Faktor Risiko Penyakit Degeneratif dan Keganasan di Masyarakat

Tabel 1 Karakteristik Responden berdasarkan Usia, Jenis Kelamin, Status Pernikahan, dan Posisi dalam Generasi

\begin{tabular}{|c|c|c|c|c|c|c|c|c|}
\hline \multirow{2}{*}{$\begin{array}{c}\text { Distribusi } \\
\text { Usia } \\
\text { (Tahun/\%) }\end{array}$} & \multicolumn{2}{|c|}{ Jenis Kelamin (\%) } & \multicolumn{3}{|c|}{ Status Pernikahan (\%) } & \multicolumn{3}{|c|}{ Generasi (\%) } \\
\hline & Laki-laki & Perempuan & Nikah & Belum & $\begin{array}{l}\text { Janda } \\
\text { /Duda }\end{array}$ & 1 & 2 & 3 \\
\hline $\begin{array}{l}18-24 \\
(14,7)\end{array}$ & $13(38,2)$ & $21(61,8)$ & $7(20,6)$ & $2779,4)$ & 0 & 0 & $10(29,4)$ & $\begin{array}{c}24 \\
(70,6)\end{array}$ \\
\hline $\begin{array}{l}25-34 \\
(11,3)\end{array}$ & $9(34,6)$ & $17(65,4)$ & $20(76,9)$ & $5(19,2)$ & $1(3,8)$ & 0 & $21(84)$ & $4(16)$ \\
\hline $\begin{array}{l}35-44 \\
(13,9)\end{array}$ & $9(28,1)$ & $23(71,9)$ & $30(93,8)$ & 0 & $2(6,3)$ & 0 & $28(87,5)$ & $3(9,4)$ \\
\hline $\begin{array}{l}45-54 \\
(28,6)\end{array}$ & $22(33,3)$ & $44(66,7)$ & $59(89,4)$ & $1(1,5)$ & $6(9,1)$ & $5(7,6)$ & $55(83,3)$ & $5(7,6)$ \\
\hline$>55(31,6)$ & $19(26)$ & $54(74)$ & $57(78,1)$ & $2(2,7)$ & $1419,2)$ & 14 19,7) & $53(74,6)$ & $4(5,6)$ \\
\hline Total & $72(31,2)$ & $159(68,8)$ & $173(74,9)$ & $35(15,2)$ & $23(10)$ & $19(8,3)$ & $\begin{array}{c}167 \\
(73,2)\end{array}$ & $\begin{array}{c}40 \\
(17,5)\end{array}$ \\
\hline
\end{tabular}

dan juga osteoartritis (Gambar 1). Persentase terbanyak adalah hipertensi baik pada generasi $1(19,9 \%)$ atau $2(4,8 \%)$ dan dari pasangan $(14,3 \%)$, keluarga pasangan (19\%), serta saudara segenerasi $(14,3 \%)$. Penyakit lain yang terdeteksi adalah asma, alergi, penyakit jantung, dispepsia, dan tuberkulosis. Dari 106 responden yang datang ke puskesmas dengan keluhan bukan PTM, ditemukan 17 (16\%) responden yang menderita PTM (Tabel 3).

\section{Pembahasan}

Sebanyak 183 responden dari 231 responden mempunyai faktor risiko penyakit degeneratif seperti hipertensi, jantung, osteoartitis, serta keganasan yang didapat baik dari generasi ibu maupun bapak. Penelitian yang dilakukan oleh Wattendorf dan Hadley ${ }^{5}$ menyatakan bahwa dengan menggambarkan faktor risiko penyakit dari keluarga dapat menggambarkan pengaruh genetik, lingkungan, dan juga perilaku. Riwayat penyakit keluarga yang digambarkan pada genogram menjadi acuan untuk merencanakan skrining yang diperlukan oleh individu dan keluarga, serta untuk kegiatan edukasi dan promosi kesehatan yang dapat dilakukan oleh dokter di tempat praktik. Menurut penelitian yang dilakukan oleh McNeill dkk. ${ }^{6}$ menyatakan bahwa riwayat keluarga dengan penyakit jantung merupakan faktor risiko bermakna terhadap kejadian penyakit tersebut di masa mendatang. Sebagian besar $(74,9 \%)$ dari responden sudah

Tabel 2 Distribusi Responden dan Anggota Keluarga Responden berdasarkan Kebiasaan Merokok

\begin{tabular}{lcccc}
\hline \multirow{2}{*}{$\begin{array}{c}\text { Usia } \\
\text { (Tahun) }\end{array}$} & \multicolumn{2}{c}{$\begin{array}{c}\text { Jumlah Responden yang Merokok } \\
(\%)\end{array}$} & \multicolumn{2}{c}{$\begin{array}{c}\text { Jumlah Anggota Keluarga Responden } \\
\text { yang Merokok (\%) }\end{array}$} \\
\cline { 2 - 5 } & Ya & Tidak & Ya & Tidak \\
\hline $18-24$ & $8(23,5)$ & $19(55,9)$ & $12(35,3)$ & $7(44,1)$ \\
$25-34$ & $9(34,6)$ & $12(46,2)$ & $14(53,8)$ & $5(26,9)$ \\
$35-44$ & $7(21,9)$ & $21(65,6)$ & $9(28,1)$ & $4(59,4)$ \\
$45-54$ & $17(25,8)$ & $39(59,1)$ & $31(47)$ & $10(37,9)$ \\
$>55$ & $11(15,1)$ & $60(82,2)$ & $29(39,7)$ & $3(56,2)$ \\
Total & $52(22,5)$ & $151(65,4)$ & $95(41,1)$ & $29(46,3)$ \\
\hline
\end{tabular}


Tabel 3 Faktor Risiko Penyakit Keganasan dan Degeneratif pada Responden dan Keluarganya

\begin{tabular}{lccccccc}
\hline \multirow{2}{*}{ Penyakit } & \multicolumn{7}{c}{ Asal Penyakit } \\
\cline { 2 - 7 } & Keganasan & Hipertensi & DM & Strok & OA & Jantung & $\begin{array}{c}\text { Penyakit } \\
\text { Lain }\end{array}$ \\
\hline Generasi 1 bapak & 1,3 & 19,9 & 6,1 & 5,2 & 1,7 & 13 & 24,7 \\
Generasi 2 bapak & 0,9 & 4,8 & 1,3 & 0,4 & 16,9 & 0,9 & 2,6 \\
Generasi 1 ibu & 2,6 & 8,2 & 4,3 & 6,1 & 1,7 & 8,2 & 18,2 \\
Generasi2 ibu & 0,4 & 5,6 & 1,3 & 1,7 & 0,4 & 0,9 & 2,2 \\
Pasangan & 0 & 14,3 & 3,5 & 3,9 & 0 & 3 & 13,9 \\
Keluarga pasangan & 0,9 & 19 & 8,2 & 4,8 & 0 & 9,1 & 16,5 \\
Saudara segenerasi & 1,7 & 14,3 & 3,9 & 1,3 & 0,4 & 0 & 15,2 \\
Anak & 0,4 & 2,6 & 0,4 & 0 & 0 & 1,7 & 15,2 \\
Cucu & 0 & 0 & 0 & 0 & 0 & 0 & 1,3 \\
\hline
\end{tabular}

menikah sehingga pembuatan genogram bukan hanya untuk individu tersebut, tetapi juga untuk pasangan karena faktor risiko dari pasangan berdampak kepada keturunannya.

Sebagian besar $(73,2 \%)$ dari responden merupakan generasi kedua, yaitu posisi sebagai anak. Keadaan ini menunjukkan bahwa yang bersangkutan mempunyai faktor risiko dari generasi sebelumnya dan selanjutnya kemungkinan risiko tersebut akan diturunkan pada generasi berikutnya. Penelitian yang dilakukan oleh McNeill dkk. ${ }^{6}$ menyatakan dari genogram keluarga sebanyak $89 \%$ responden dapat menggambarkan kejadian penyakit dan kematian pada 3 generasi. Lebih dari duapertiga memiliki riwayat DM pada generasi pertama dan seluruh responden memiliki riwayat penyakit kardiovaskular pada keluarganya. ${ }^{6}$ Penelitian oleh Werner-Lin dkk. ${ }^{8}$ menemukan genogram dapat mendeteksi faktor risiko kanker dan sekaligus melakukan konseling genetik pada individu. ${ }^{7}$ Penelitian oleh Rahimi dkk. ${ }^{8}$ tentang kegunaan genogram dalam mendeteksi faktor risiko OCD pada keluarga didapatkan riwayat yang sama pada generasi sebelumnya.

Pengetahuan mengenai faktor risiko dan riwayat keluarga dapat menjadi panduan dalam mengembangkan rekomendasi penatalaksanaan penyakit berbasis risiko. ${ }^{5}$ Risiko adalah faktor yang meningkatkan kemungkinan/probabilitas suatu kejadian yang tidak diinginkan. ${ }^{4}$ Salah satu risiko yang tergambar dari genogram adalah kebiasaan merokok. Pada penelitian ini, tampak kebiasaan merokok sudah dilakukan semejak usia muda. Keadaaan ini sesuai dengan hasil Riskesdas Jawa Barat 2007 yang menyatakan

Tabel 4 Kesesuaian Keluhan dengan Persepsi terhadap Diagnosis, n (\%)

\begin{tabular}{lcccccc}
\hline $\begin{array}{c}\text { Jumlah } \\
\text { Responden } \\
\text { dengan } \\
\text { Keluhan/ } \\
\text { Diagnosis }\end{array}$ & $\begin{array}{c}\text { Jumlah } \\
\text { Responden } \\
\text { yang } \\
\text { Menderita } \\
\text { Penyakit } \\
\text { Degeneratif } \\
\mathbf{( \% )}\end{array}$ & $\begin{array}{c}\text { Jumlah } \\
\text { Responden } \\
\text { yang } \\
\text { Menderita } \\
\text { Bukan } \\
\text { Penyakit } \\
\text { Degeneratif } \\
\mathbf{( \% )}\end{array}$ & $\begin{array}{c}\text { Jumlah } \\
\text { Responden } \\
\text { yang } \\
\text { Menderita } \\
\text { Penyakit } \\
\text { Keganasan } \\
\mathbf{( \% )}\end{array}$ & $\begin{array}{c}\text { Jumlah } \\
\text { Responden } \\
\text { yang } \\
\text { Menderita } \\
\text { Alergi, } \\
\text { Asthma } \\
\mathbf{( \% )}\end{array}$ & $\begin{array}{c}\text { Tidak } \\
\text { diisi }\end{array}$ & Total \\
\hline Degeneratif & $76(62,3)$ & $4(3,3)$ & 0 & $12(9,8)$ & $30(24,6)$ & $122(100)$ \\
Bukan & $17(16)$ & $34(32,1)$ & $3(2,8)$ & $12(11,3)$ & $40(37,7)$ & $106(100)$ \\
Tidak diisi & 0 & 0 & $3(100)$ & 0 & 0 & $3(100)$ \\
Total & $\mathbf{9 3}(\mathbf{4 0 , 3 )}$ & $\mathbf{3 8 ( 1 6 , 5 )}$ & $\mathbf{3 ( 2 , 6 )}$ & $\mathbf{2 4}(\mathbf{1 0 , 4 )}$ & $\mathbf{7 0}(\mathbf{3 0 , 3 )}$ & $\mathbf{2 3 1 ( 1 0 0 )}$ \\
\hline
\end{tabular}


perilaku merokok penduduk 15 tahun ke atas cenderung meningkat dari 34,2\% tahun 2007 menjadi 36,3\% tahun 2013. ${ }^{4}$ Risiko terjadinya penyakit jantung koroner dan strok meningkat sebesar 2-4 kali pada perokok dibanding dengan yang tidak merokok. Risiko kejadian kanker paru pada laki-laki perokok adalah 23 kali dan 13 kali pada perempuan perokok. Menggali faktor risiko dengan genogram dapat memperkaya rencana intervensi dan strategi penatalaksanaan untuk pasien baik penatalaksanaan medis atau nonmedis. ${ }^{9-10}$ Genogram ini merupakan cara untuk memahami keluarga dengan faktor risikonya sehingga penatalaksanaan yang telah diberikan sesuai dengan situasi dan kondisi individu dan juga keluarga masing-masing. ${ }^{11-13}$ Keterbatasan yang ditemukan penelitian ini adalah recall bias seperti kemampuan responden dalam mengingat faktor risiko dan riwayat penyakit pada keluarganya.

Simpulan, bahwa genogram efektif untuk mendeteksi secara cepat faktor risiko penyakit degeneratif dan keganasan pada individu dan keluarga serta faktor risiko lainnya sehingga penggunaan genogram ini mampu dilaksanakan di setiap praktik dokter sebagai suatu langkah untuk mendapatkan data dan masalah kesehatan pasien serta keluarganya secara cepat, murah, dan sederhana.

\section{Daftar Pustaka}

1. Rahajeng E, Tuminah S. Prevalensi hipertensi dan determinannya di Indonesia. Maj Kedokt Indon. 2009;59(12):580-7.

2. WHO. The World Health Report 2002: reducing risks, promoting healthy life. Geneva: WHO; 2002.

3. Kementrian Kesehatan RI. Riset Kesehatan Dasar 2013. Jakarta: Kementerian Kesehatan RI; 2013.
4. Yoon PW, Scheuner MT, Jorgensen C, Khoury MJ. Developing family healthware: a family history screening tool to prevent common chronic diseases preventing chronic disease. Prev Chronic Dis. 2009;6(1):1-11.

5. Wattendorf DJ, Hadley DW. Family history: the three-generation pedigree. AAFP. 2005;72(3):441-8.

6. McNeill JA, Cook J, Mahon M, Rauschhuber M, Jones ME, Estrada R. Family history: valueadded information in assessing cardiac health. AAOHN J. 2008;56(7):297-305.

7. Werner-Lin A, Gardner DS. Family illness narratives of inherited cancer risk: continuity and transformation. Fam Syst Health. 2009;27(3):201-12.

8. Rahimi A, Haghihi M, Shamsaei H. Pure obsessive compulsive disorder in three generations. Iran J Psychiatry Behav Sci. 2015;9(2):1-3.

9. Pereira AP, Teixeira GM, Bressan CA, Martini JG. The genogram and the eco-map in family health nursing care. Rev Bras Enferm. 2009;62(3):407-16.

10. Rempel GR, Neufeld A, Kushner KE. Interactive use of genograms and ecomaps in family caregiving research. J Fam Nurs. 2007; 13(4):403-19.

11. Juré E, Iguenane J, Toudonou A, Azondekon A, Gagnayre R. The usefulness of a genogram as a tool in therapeutic patient education: an exploratory study of parents of children living with HIV/AIDS in Benin. Sante Publique. 2010;22(1):11-22.

12. Chrzastowski SK. A narrative perspective on genograms: revisiting classical family therapy methods. Clin Child Psychol Psychiatry. 2011;16(4):635-44.

13. Leonidas C, Santos MA. Family relations in eating disorders: the genogram as instrument of assessment. Gencia \& Saude Coletiva. 2015;20(5):1435-47. 